\title{
The remotely controlled underwater robot system
}

\author{
Cristian $\mathrm{Nita}^{1,}$, Dumitru Deleanu ${ }^{2 *}$, and Ionut Voicu ${ }^{3}$ \\ ${ }^{1}$ Doctoral School of Mechanical Engineering, Electromechanical Faculty, 900663 Mircea cel Batran \\ Street, Romania \\ ${ }^{2}$ Constanta Maritime University, Department of General Engineering Sciences, 104 Mircea cel \\ Batran street, ZC 900663, Constanta, Romania \\ ${ }^{3}$ Electromechanical Faculty, Engineering Sciences in Mechanics and Environment Department, \\ 900663 Mircea cel Batran Street, Romania
}

\begin{abstract}
The remotely controlled underwater robot system is used extensively by the scientific community to study the ocean, in support of diving operations, in military use, in educational outreach, in broadcast use. We built this system which has three components: 1) the surface control interface; 2) the intermediate device; 3) the robot itself. The presence of this robot replaces human activities where access is not allowed or life is endangered. The novelty of this device is the construction of component 2 (intermediate), which represents a storage frame for the underwater robot and part of the control umbilical cord. The frame descends with the robot to the depth of surveillance from where the robot leaves the storage frame and is further controlled to the research objective. The surveillance function is performed from the intermediary with the help of a video camera. The video camera is the IP type and can be accessed through the data over power network. The movement of the underwater device is accomplished by means of 8 electric motors ( 4 for horizontal control and 4 for vertical control). The robot has data acquisition and storage systems and piloting systems. The purpose of building this robot is educational research.
\end{abstract}

\section{Introduction}

The remotely controlled underwater robot system is used extensively by the scientific community to study the ocean, in support of diving operations, in military use, in educational outreach, in broadcast use (in the filming of several documentaries, coastguard services).

The remote controlled underwater robot system (RCURS) was specially designed for underwater activities that are generally deep [1]. It is connected to the ship by an umbilical cord, resistant to adverse conditions and to great depths, often used in conjunction with TMS (Tether Management System). The TMS can be a garage-type device that includes the

\footnotetext{
${ }^{*}$ Corresponding author: dumitru-deleanu@yahoo.com
} 
RCURS during its dive, or it can be a sled-like device that only carries the laying cable. The purpose of the TMS is to extend or shorten the umbilical cord, in order to dampen the power draw of the water currents.

As a use and historian, this system has been and can be used to rescue and recover objects at a great depth, assisting in the development of oil platforms where diving access is impossible, in initiating underwater constructions and repairing and maintaining them later and also they can be used extensively by the scientific community in exploring the ocean [2].

As technological variants can be designed to different sizes [3]: Micro - very small and very light (weigh less than $3 \mathrm{~kg}$ ) - used as an alternative for divers, especially in places where a diver could not have access (such as a canal, pipes or other small cavities); Mini weigh about $15 \mathrm{~kg}$ (they are also used as an alternative for divers); · General - usually with less than 5 horsepower (propulsion); Light Workclass - with less than 50 HP (horsepower); Heavy Workclass - usually with less than 220HP; Trenching \& Burial - with more than 200 $\mathrm{HPr}$, but often no more than $500 \mathrm{HP}$.

\section{Recommended solution}

\subsection{Main system structure}

The remote controlled underwater robot system is composed of three components: 1) the surface control interface; 2) the intermediate device; 3 ) the robot itself. The structure of the robot body is presented in the Fig. 1 .

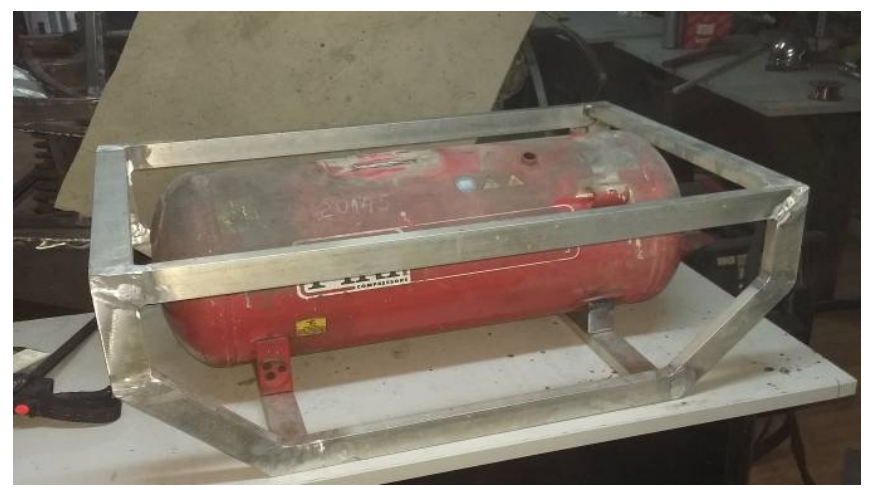

Fig. 1. The structure of the robot body

The control of the underwater robot is made from the surface with the help of specialized software installed on the computer (Fig. 1). The control signal is transmitted from the surface computer through an umbilical cord to the underwater robot. Both the electrical energy required to operate the underwater robot and the control signal are transmitted through two electrical conductors, through the data over power network system.

The $2^{\text {nd }}$ component, called intermediate, represents a storage frame for the underwater robot and part of the control umbilical cord (Fig. 2). The frame descends with the robot to the depth of surveillance from where the robot leaves the storage frame and is further controlled to the research objective. Component number 2 is provided with a surface controlled winch that allows the robot to receive only the umbilical cord length required for movement, thus avoiding the possibility of tangling the control cord in foreign bodies. 


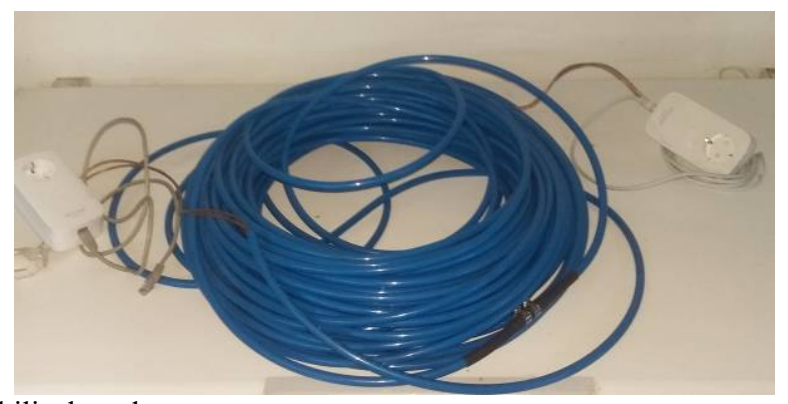

Fig. 2. The control umbilical cord

The surveillance function is performed from the intermediary with the help of a video camera. The video camera is the IP type and can be accessed through the data over power network.

Component number 3, the underwater robot, hosts all motion control and navigation systems (Fig. 3).

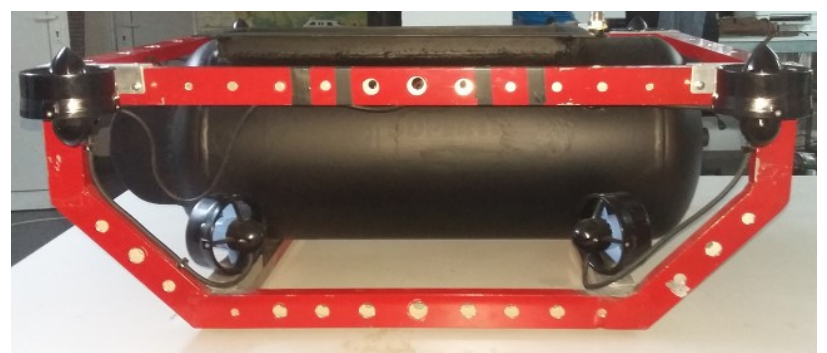

Fig. 3. The underwater robot

Motion control is carried out by means of four electric motors for horizontal control and another 4 electric motors for vertical control. Inside the robot's watertight housing are installed two video cameras, one front for navigation and one superior with interior and intermediate view, having a guiding role towards it. The electronic and electrical system installed in the underwater robot is composed of 5 power sources with an input from 220 volts $\mathrm{AC}$ and 12 volts $\mathrm{DC}$, these have the role of supplying electric motors and auxiliary systems (Fig. 4).
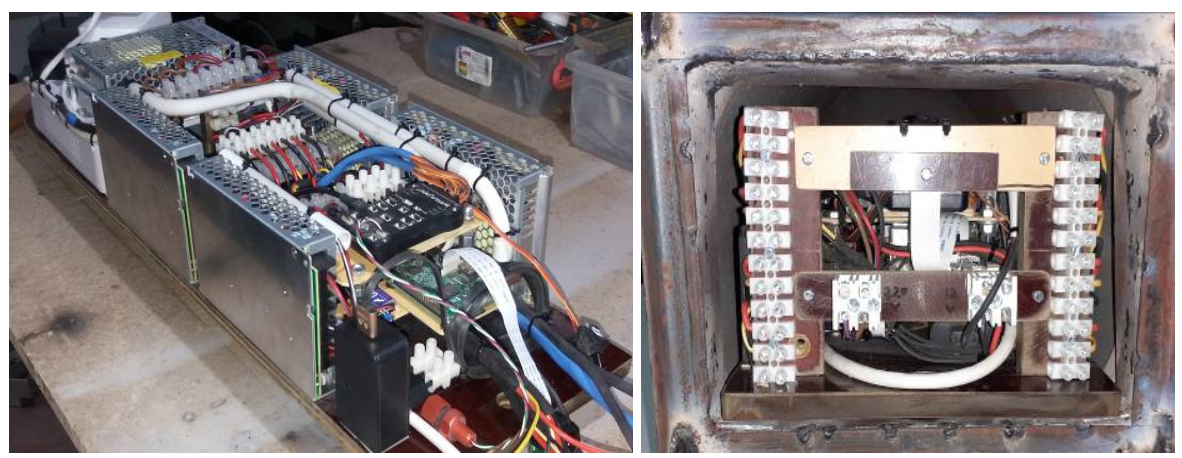

Fig. 4. The electronic and electrical system

The underwater robot is powered by an alternating voltage of 220 volts from the surface. 


\subsection{The auxiliary structure}

The auxiliary systems are the following: the data over network system, the communication system formed by a computer from the raspberry pi series, and the multi-device "pixhawk" pilot system. The on-board computer communicates with the "pixhawk" and sends the surface controls to it (Fig. 5).

Fig. 5. The multi-device pixhawk pilot system
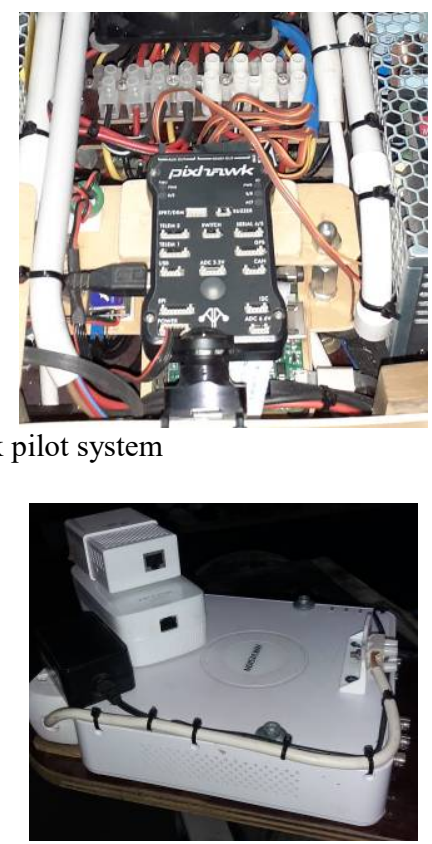

Fig. 6. The analog-to-digital signal converter

The robot is provided with indication for depth, electronic compass, temperature and inclination angle. The video signal is transmitted using an analog-to-digital signal converter, and accessed over a network over power network over IP (Fig. 6). This system is located inside the robot housing on a platform (Fig. 7).

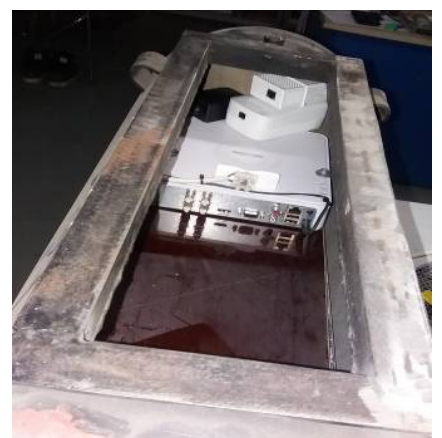

Fig. 7. The platform with signal converter

\section{Experimental researches}

The general structure is fixed on the frame platform. The frame platform descends with the robot itself to a depth of surveillance from where the robot leaves the storage frame and is further controlled to the research objective (Fig. 8). 


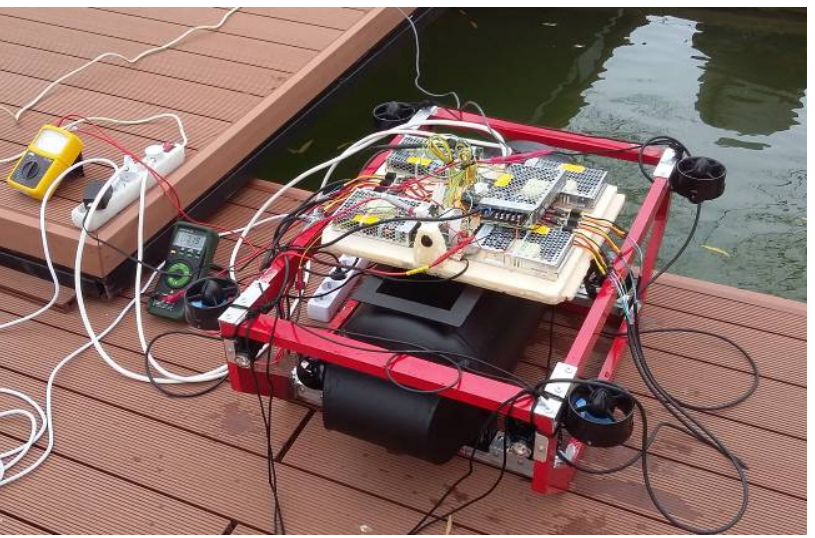

Fig. 8. The general structure of device

The component number 2 is provided with a surface controlled winch that allows the robot to receive only the length of the control cord required for movement, thus avoiding the possibility of entanglement in foreign bodies.

The robot moves in a horizontal or vertical direction with 4 electric motors on each direction (Fig. 9).

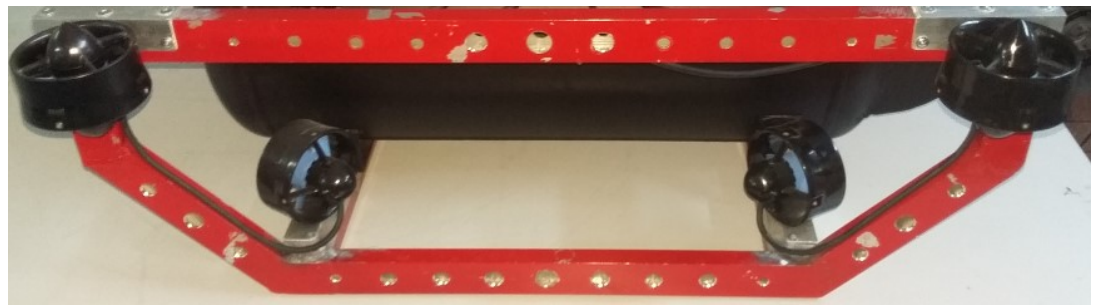

Fig. 9. Front view - electric motors for moving

The technology for making this robot has been developed for educational and research purposes. Its modular design allows configuration to meet the specific needs of a research, just as military special mission vehicles are designed [4].

\section{Conclusions}

Depending on the research to be carried out, this underwater robot can be equipped with various sensory and sampling devices. The purpose of this paper is to present the technological way of making such a robot for teaching and research purposes.

The novelty of this device is the construction of component 2 (intermediate), which represents a storage frame for the underwater robot and part of the control umbilical cord. The frame descends with the robot to the depth of surveillance from where the robot leaves the storage frame and is further controlled to the research objective.

Learning the technological modalities of achievement teaches students to acquire the basic skills in designing ships and submarines, and encourages them to explore the architecture and concepts of naval engineering. 
This paper has financial support from the Constanta Maritime University under assistance project PNIII-P1-1.2-PCCDI-2017-0404 /31PCCDI/2018, Holistic on the Impact of Renewable Energy Sources on Environment and Climate-HORESEC.

\section{References}

1. D. Dumitru, C. Vlad, Diving and underwater vehicles (Scientific and Encyclopedic Edition, Bucharest,1986)

2. D.Dumitru, C. Vlad, Underwater interventions (Technical Publishing House, Bucharest, 1982)

3. R. Sundar, M. Dheepak, P. Veera Kumar, PC based remote operated underwater vehicle for marine surveillance, Int.J.of Civil Engineering and Technology, 8, Issue 6, 716-721 (2017)

4. Pascu.E., Royal Netherlands Navy- Sea-Wasp ROV, J. Defense Romania, 20 iV (2020) 